\title{
City as Relationship
}

\author{
Martha Johnson \\ University of Minnesota
}

\section{Introduction}

Volume XX (Spring 2011) of Frontiers: The Interdisciplinary Journal of Study Abroad takes a thematic focus on "Study Abroad and the City." As part of the Global Cities Seminar hosted by CAPA International Education in Vancouver in May 2011, participants were asked to consider the use of the city as text, the city as document, and the city as cultural informant. The articles featured in the journal and at the workshop presented an array of case studies and compelling arguments for ensuring active engagement with the physical environment that various urban spaces provide as educative tools for students abroad.

During the discussion that followed the presentations, an aspect not fully explored either in the journal or on the panel occurred to me. What about the city as a relationship? As Rodríguez and Rink suggest in their article Performing the City: Engaging the High Tech Flaneur (2011), the ability of the city to elicit a visceral and emotional response is a powerful but often untapped element of the experience abroad.

At the most obvious and basic level, travelers inevitably articulate their experience of destinations in the language of emotion: "I did not really like Venice, but I loved Rome." I would like to give a bit of consideration to the emotional relationship travelers, and more specifically students on programs abroad, have with cities. I would also like to suggest some of the opportunities "the city as relationship" might offer if explored or presented as such.

Cities tend, generally speaking, to be feminized, but are inevitably represented in humanized terms. They take on the culture and identity characteristics representative of their histories and roles in relationship to power structure. They are exoticized, re-appropriated, and reduced to simplistic imagery presented as travel-porn in the pages of Conde Nast Traveler, National Geographic, or the Lonely Planet guides. Tourists buy t-shirts extolling their affairs with cliché pronouncements such as "I $\bullet$ New York." Positioning the nature of the experience more actively in relationship terms might prove a useful tool for a student looking to experience a place. 


\section{If one had but a single glance to give the world, one should gaze on Istanbul.}

Alphonse de Lamartine

\section{First date}

Why does one destination or program appeal to an individual? We can cite numerous rational and practical reasons why students select the programs and places they do: destination, curriculum, duration, cost, professional goals, etc. And yet, when asked why they chose a certain program, students frequently attempt to verbalize an almost elusive allure the place held in their imagination or perceptions. Often the resonating image is imbedded in their subconscious as part of their personal narrative history (a culmination of movies, books, TV, music, etc., imagery and associations they have internalized over a lifetime) and may not be a motivation about which they themselves are cognizant. The literary and film canons are filled with works that are, in essence, a homage to cities and exotic places. When the inspiration is an artistic representation the attraction to the site is the travel equivalent of "eyes meeting across a room." Data supports the notion that popularity in films or television will influence choice of site. For example, study abroad numbers to New Zealand increased over 300\% in what our office dubbed the "Lord of the Rings" effect, and Olympic Games sites usually enjoy a pre- and post-Olympic spike in numbers.

I have seen Japanese anime, salsa dancing, the Crocodile Hunter, and Guy Ritchie films all referenced in application essays. Yet there is something compelling in the idea that such representations resonate to the degree that they inform someone's choice of destination for travel and study abroad. In many cases the student develops a "crush" on a destination and a fantasized ideal of a particular place. An attraction to a city or culture develops that is different from other places and that becomes the impulse, conscious or not, to explore further.

The student then applies some of the same strategies before committing. He or she reviews photos and talks to others who know about the place. And eventually the student commits to initiating the relationship. The anticipation and preparation are analogous to a long-awaited first date, and in many cases a "blind" date, by the time the student departs. 


\section{Venice is like eating an entire box of chocolate liqueurs in one go. Truman Capote}

\section{Moving in together}

The response students have upon arrival to a place is often one of pure emotion. The students may immediately feel they "love" or "hate" a place and instructors or on-site program staff may find themselves doing ad hoc psychoanalysis of these students. In many cases the site triggers a response based on the student's expectations, but to deny the emotional impact is problematic. In the same way we might ask someone to describe what they "like" about a friend or romantic partner asking students to engage with their emotional reaction to the site through exercises or assignments will allow them to engage intellectually by giving credence to the emotional response. As Rink and Rodríguez point out, the psycho-geographical response to place may not be conscious on the students' part but will influence their experience significantly (2011).

The culture curve initially developed by Sverre Lysgaard, in the 50's and widely referenced in education abroad puts this trajectory into a visual curve of ups and downs, oddly reminiscent of a romance or new friendship. The student begins the relationship in a euphoria, eventually getting to know the city in a more intimate way beyond the public face and superficial elements. The evolution mirrors the process people have in getting to know individuals more intimately. This leads to frustration and challenges but also to the satisfaction and gratification that a deeper and more accepting relationship provides.

Throughout a program, opportunities to address the psycho-geographical responses to this complexity can be integrated. As programs increasingly seek to access facets of cities and cultures not historically represented in study abroad this becomes increasingly crucial. Activities that include marginalized and nontraditional populations, or transitional or underdeveloped neighborhoods, need to recognize the emotional responses such visits will elicit, including fear, guilt, anger, and hopelessness. Particularly in instances where the experience of difference elicits fear, addressing the emotional dimension can allow for a dialogue on the context of difference and help the student address and, hopefully, conquer responses that may be based in stereotypes or misperceptions.

In support of the simile of city as relationship, these responses are often verbalized in terms that humanize or objectify the city. A student who visits a neighborhood that has transient or immigrant populations will often respond: "Dublin is not what I thought it would be." In such cases the reaction to an area becomes for the student an aspect of the city's personality like a bad habit or trait. 
Inevitably even the most idyllic location proves disappointing on some level. Students will learn that the place they "love" has flaws. As the culture curve reminds us, once the "honeymoon" is over, students often have a feeling of being let down. By presenting this phenomenon in relationship terms, we can point out the richness that comes with relationships once we truly get to know the other.

America is my country and Paris is my hometown. Gertrude Stein

When I lived in Hong Kong, I felt that Hong Kong was my family. Jet Li

\section{Committing to a long-term relationship}

So how do we address the student's relationship to place? The emotional dimension may be overlooked or deemed anti-intellectual, and certainly can be if, post-experience, it is reduced to "Did you like it?". Or the relationship can allow the student to approach the city as a complex and multifaceted entity that they seek to truly know. To know a person is to understand that person's history, family, personality, strengths, weaknesses, hopes, and aspirations. To know a person is to experience both the public image and private self. I would argue that to know a city is no different than to know a person.

The field of education abroad is often a victim of its own mythology (find the real, make lifelong friendships in three weeks, become a global citizen, etc.). One aspect of this idea of city as relationship that I find most appealing is that it is one to which a student can aspire and at which he or she can succeed. So perhaps when challenging students to make friends we should integrate the discussion of the city as a friend. Knowing a city can be one of the most rewarding relationships travelers can have and provide all of the cross-cultural richness we want them to experience. Cities can welcome you, romance you, and lie to you. But you can also establish a relationship with a city that will help you learn a little more about yourself, and this can last a lifetime.

\section{References}

Rodríguez K and Rink B. (2011) "Performing Cities: Engaging the High Tech Flaneur", Frontiers: The Interdisciplinary Journal of Study Abroad XX 103-117

Lysgaard, Sverre. (1955). "Adjustment in a Foreign Society: Norwegian Fulbright Grantees Visiting the United States." International Social Science Bulletin 7:45-51. 